\title{
PENGARUH PEMERIKSAAN PAJAK DAN SANKSI PERPAJAKAN TERHADAP KEPATUHAN WAJIB PAJAK PADA KANTOR PELAYANAN PAJAK PRATAMA MANADO
}

\author{
Jeremiah Reinhart Assa ${ }^{1}$, Lintje Kalangi ${ }^{2}$, Winston Pontoh ${ }^{3}$ \\ ${ }^{123}$ Jurusan Akuntansi, Fakultas Ekonomi dan Bisnis, Universitas Sam Ratulangi, Jl. Kampus Bahu, Manado, \\ 95115, Indonesia \\ E-mail: itsmejr@rocketmail.com
}

\begin{abstract}
One of the largest state revenues comes from the tax sector. Tax receipts are a major source of financing and national development to improve people's welfare. One of the tax revenues is derived from Income Tax (PPh). Sanctions and tax audit is one of the factors that influence taxpayer compliance. This study aims to determine the effect of sanctions and tax audits on taxpayer compliance in paying taxes. This research uses quantitative research method. The results showed that tax audit and sanctions have a significant effect on taxpayer compliance in paying taxes. This is a reference so that supervision in the form of inspection can be maximized so as to improve taxpayer compliance in paying taxes.
\end{abstract}

Keywords: tax audit, tax sanctions, tax compliance

\section{PENDAHULUAN}

Pendapatan negara yang besar berasal dari pajak. Pemerintah melalui Direktorat Jenderal Pajak telah menetapkan misi fiskal agar perencanaan pembangunan tetap berlanjut, dengan pajak sebagai komponen strategisnya (Amanda, 2014; Mutia, 2014). Pemeriksaan pajak merupakan salah satu faktor yang mempengaruhi kepatuhan wajib pajak. Penegakkan hukum (law enforcement) agar memunculkan kepatuhan wajib pajak dalam memenuhi kewajiban perpajakan (tax compliance), sehingga memiliki dampak meningkatnya penerimaan pajak yang akan masuk dalam kas negara, merupakan tujuan dilakukannya pemeriksaan pajak. Pemeriksaan pajak merupakan pagar penjaga agar WP tetap memenuhi kewajiban perpajakannya (Suhendra, 2010 dalam Mandagi, 2014). Faktor lain yang mempengaruhi kepatuhan WP adalah pemberian sanksi perpajakan, yang diberikan kepada WP yang tidak memenuhi kewajiban perpajakannya. Harus ada sanksi perpajakan bagi para pelanggarnya. Bila WP memandang bahwa sanksi perpajakan akan merugikannya, maka wajib pajak akan melakukan pemenuhan kewajiban perpajakannya (Nugroho, 2006 dalam Utami, 2013). Tujuan penelitian ini adalah untuk mengetahui seberapa besar pengaruh Pemeriksaan Pajak dan Sanksi Perpajakan terhadap Kepatuhan Wajib Pajak pada Kantor Pelayanan Pajak (KPP) Pratama Manado.

\section{TINJAUAN PUSTAKA}

Akuntansi Pajak. Besarnya pajak terutang ditetapkan berdasarkan laporan keuangan yang disusun oleh perusahaan merupakan pengertian dari akuntansi pajak (Agoes \& Estralita, 2013:10). Sedangkan Tunggal (2012:6) menyatakan, "akuntansi pajak adalah mencakup penyusunan surat pemberitahuan pajak dan mempertimbangkan konsekuensi perpajakan dari transaksi usaha yang direncanakan atau mencari alternatif tindakan lainnya."

\section{Pajak}

Definisi Pajak. Prof. Dr. Rochmat Soemitro, S.H. berpendapat, "pajak merupakan iuran rakyat kepada kas negara berdasarkan Undang-Undang (yang dapat dipaksakan) dengan tiada 
mendapat jasa timbal (kontraprestasi) yang langsung dapat ditunjukkan dan yang digunakan untuk membayar pengeluaran umum."

Fungsi Pajak. Menurut Waluyo (2011:6) dan Resmi (2013:3), terdapat dua fungsi pajak yaitu fungsi penerimaan (budgetair) dan fungsi mengatur (regulerend).

Sistem Pemungutan Pajak. Menurut Waluyo (2011:17) dan Mardiasmo (2016:9), ada tiga sistem pemungutan pajak, yaitu sistem official assessment, self assessment, dan with holding.

Hambatan Pemungutan Pajak. Hambatan terhadap pemungutan pajak menurut Mardiasmo (2016:10), ialah perlawanan pasif dan perlawanan aktif.

Tarif Pajak. Mardiasmo (2016:11) mengatakan, "terdapat 4 macam tarif pajak, yaitu tarif sebanding/proporsional, tarif tetap, tarif progresif, dan tarif degresif."

\section{Pemeriksaan Pajak}

Definisi Pemeriksaan Pajak. Mardiasmo (2016:56) menyatakan, "pemeriksaan pajak adalah serangkaian kegiatan menghimpun dan mengelola data, keterangan, dan/atau bukti yang dilaksanakan secara objektif dan profesional berdasarkan suatu standar pemeriksaan untuk menguji kepatuhan pemenuhan kewajiban perpajakan dan/atau untuk tujuan lain dalam rangka melaksanakan ketentuan peraturan perundang-undangan perpajakan.”

\section{Sanksi Perpajakan}

Definisi Sanksi Perpajakan. Mardiasmo (2016:62) mengatakan, "sanksi perpajakan merupakan jaminan bahwa ketentuan peraturan perundang-undangan perpajakan (norma perpajakan) akan dituruti/ditaati/dipatuhi. Dengan kata lain sanksi perpajakan sebagai alat pencegah (preventif) agar wajib pajak tidak melanggar norma perpajakan.”

Jenis-Jenis Sanksi Perpajakan. Dua jenis sanksi dalam perundang-undangan perpajakan, yaitu Sanksi Administratif dan Pidana.

Penelitian Terdahulu. Ida Bagus Meindra Jaya (2016) meneliti "Pengaruh Kesadaran, Kualitas Pelayanan, Pemeriksaan dan Sanksi Perpajakan pada Kepatuhan Wajib Pajak Restoran". Hasil penelitian menunjukkan kesadaran WP, kualitas pelayanan, pemeriksaan pajak dan sanksi perpajakan berpengaruh positif pada kepatuhan WP restoran di Dinas Pendapatan Kota Denpasar. Prawagis (2016) meneliti "Pengaruh Pemahaman Atas Mekanisme Pembayaran, Persepsi Tarif dan Sanksi Pajak Terhadap Kepatuhan Wajib Pajak Usaha Mikro Kecil dan Menengah". Hasil penelitian menunjukkan bahwa terdapat pengaruh yang signifikan baik secara simultan maupun parsial.

\section{METODE PENELITIAN}

Jenis Penelitian. Deskriptif kuantitatif dengan menggunakan metode survey merupakan jenis dari penelitian ini. Sugiyono (2013:11) menyatakan, "metode survey dilakukan untuk memperoleh data dari tempat tertentu secara alamiah (bukan buatan), namun peneliti melakukan perlakuan dalam pengumpulan data, contohmya dengan mengedarkan kuesioner, tes, wawancara terstruktur dan sebagainya. Penelitian ini menggunakan metode analisis asosiatif kausal. Sugiyono (2013:55) mengatakan, "penelitian asosiatif kausal adalah penelitian yang bertujuan untuk mengetahui hubungan dua variabel atau lebih dan bersifat sebab akibat.

Tempat Dan Waktu Penelitian. Penelitian ini berlangsung pada bulan November 2017 dan bertempat di Kantor Pelayanan Pajak (KPP) Pratama Manado.

\section{Prosedur Penelitian}




\section{Gambar 1. Prosedur Penelitian}

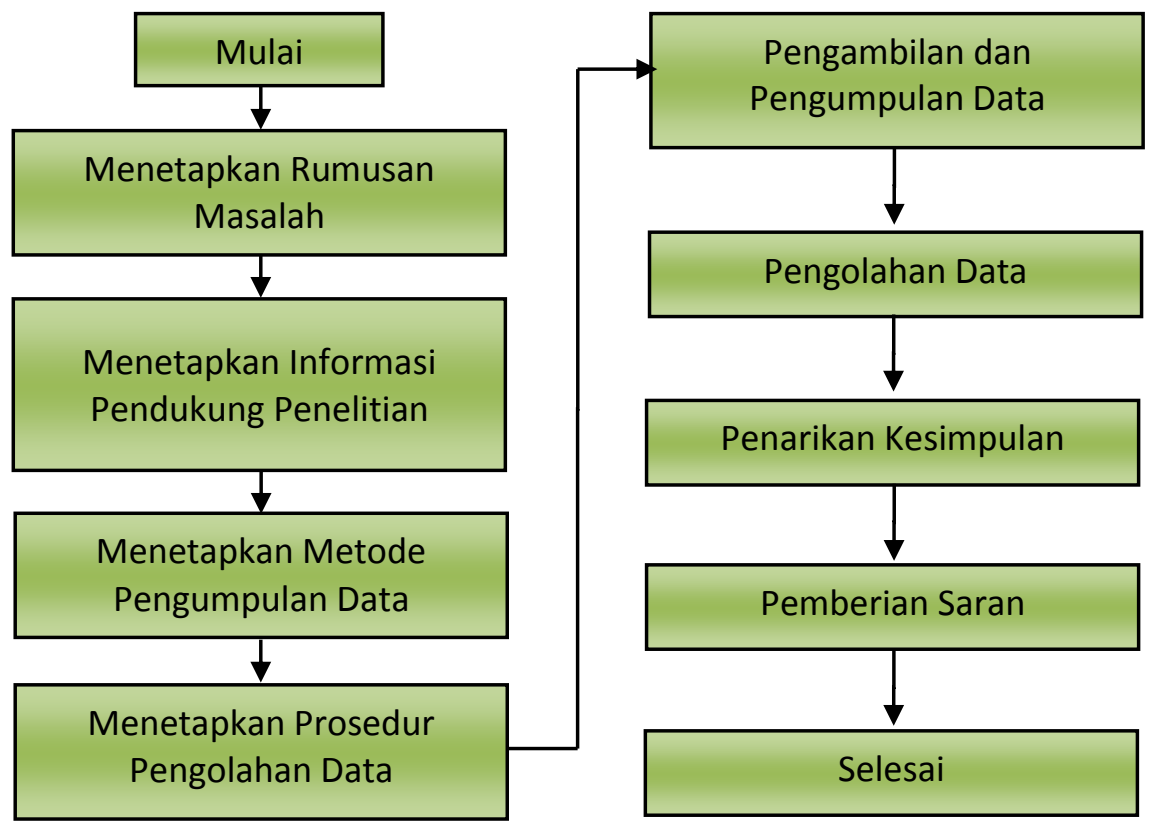

Sumber: Kerangka Berpikir Penelitian

Metode Pengumpulan Data. Teknik pengumpulan data menggunakan kuesioner. Sugiyono (2014:72) menyatakan, "kuesioner merupakan teknik pengumpulan data yang dilakukan dengan cara memberi seperangkat pertanyaan atau pernyataan tertulis untuk dijawabnya. Peneliti dapat menggunakan instrumen kuesioner untuk memperoleh data yang terkait dengan pemikiran, perasaan, sikap, kepercayaan, nilai, persepsi, kepribadian dan perilaku dari responden."

Metode Analisis. Teknik analisis data menggunakan statistik inferensial. Sugiyono (2013) mengatakan, "statistik inferensial merupakan teknik statistik yang digunakan untuk menganalisis data sampel dan hasilnya diberlakukan untuk populasi. Statistik yang digunakan adalah statistik parametris, untuk menguji parameter populasi melalui data sampel." Yang digunakan adalah uji regresi linear berganda, karena terdapat dua/lebih variabel independen dan satu variabel dependen (Santoso, 2014:149). Tahapan yang dilakukan:

a. Uji Validitas dan Reliabilitas Instrumen. Dilakukan pengujian terhadap kuesioner sebelum digunakan dalam penelitian. Pengujian validitas yang digunakan adalah pengujian validitas isi. Pengujian reliabilitas yang digunakan adalah internal consistency. Dalam penelitian ini, uji validitas dan reliabilitas instrumen dicobakan pada 63 orang sampel. Apabila nilai $r_{\text {hitung }}>r_{\text {kritis }}\left(r_{\text {hitung }}>0,30\right)$ pada uji validitas dan uji reliabilitas maka dianggap memenuhi syarat sehingga uji yang selanjutnya dapat dilakukan.

b. Uji Asumsi Klasik, merupakan persyaratan statistik yang harus dipenuhi dalam analisis regresi linear berganda. Persyaratan tersebut:

1. Uji Normalitas, dilakukan untuk melihat bahwa suatu data terdistribusi secara normal atau tidak. Normalitas data dipenuhi jika nilai statistik Kolmogrof-Smirnov dengan tingkat signifikansi<0.05 diartikan distribusi data tidak normal, tingkat signifikansi $>0.05$ diartikan distribusi data normal.

2. Uji Multikolinearitas, dilakukan untuk mengetahui apakah terdapat korelasi antar variabel bebas. Apabila terdapat korelasi, maka terjadi masalah Multikolinearitas. Seharusnya tidak terjadi korelasi diantara variabel independen, dalam model regresi yang baik. (Santoso, 2014:183). Asumsi multikolinearitas:

a. Nilai VIF $>10$ dan nilai toleransi $<0,1$ maka terjadi multikolinearitas,

b. Nilai VIF $<10$ dan nilai toleransi $>0,1$ maka tidak terjadi multikolinearitas. 
3. Uji Heteroskedastisitas. Santoso (2014:187) mengatakan, "Uji Heteroskedastisitas digunakan untuk mengetahui apakah dalam sebuah model regresi, terjadi ketidaksamaan varians residual dari satu pengamatan ke pengamatan yang lain. Jika varians residual dari pengamatan tersebut tetap, maka disebut Homoskedastisitas. Namun apabila varians berbeda, disebut Heteroskedastisitas. Model regresi yang baik adalah tidak terjadi Heteroskedastisitas. Uji statistik yang digunakan adalah uji heteroskedastisitas dengan grafik scatterplot." Namun apabila salah satu syarat asumsi klasik tidak terpenuhi, maka dapat langsung dilakukan uji hipotesis menggunakan uji statistik non-parametris yaitu uji korelasi Spearmen.

c. Uji Hipotesis

1. Uji Parsial (t-test), digunakan untuk menguji koefisien regresi secara parsial dari variabel bebas terhadap variabel terikat. Nilai probabilitas $<0,05$ maka Ho ditolak, nilai probabilitas $>0,05$ maka Ho diterima.

2. Uji Simultan (F-test), digunakan untuk melihat pengaruh dari seluruh variabel bebas terhadap variabel terikat. Nilai probabilitas $<0,05$ maka Ho ditolak, nilai probabilitas $>0,05$ maka Ho diterima.

3. Uji Koefisien Determinasi $\left(R_{2}\right.$-test), digunakan untuk melihat besarnya kemampuan variabel independen menjelaskan variabel dependen. Besarnya $\mathrm{R}$ square berada diantara 0-1 yang berarti semakin kecil besarnya $\mathrm{R}$ square, maka hubungan kedua variabel semakin lemah. Sebaliknya, jika $\mathrm{R}$ square semakin mendekati 1, maka hubungan kedua variabel semakin kuat. Menurut Sugiyono (2013:252), rumus yang digunakan:

$K D=R^{2} \times 100 \%$, dimana “KD” merupakan koefisien determinasi,"R2" merupakan koefisien korelasi.

4. Uji Regresi Linear Berganda, dilakukan apabila peneliti bertujuan untuk memperkirakan keadaan naik turunnya variabel dependen, bila variabel independen sebagai faktor prediktor dimanipulasi nilainya. Rumus yang digunakan:

$\mathrm{Y}=\mathrm{a}+\mathrm{b}_{1} \mathrm{X}_{1}+\mathrm{b}_{2} \mathrm{X}_{2}$

Dimana "Y merupakan variabel kepatuhan wajib pajak, "a" merupakan nilai konstanta, " $\mathrm{b}_{1} \mathrm{X}_{1}$ " merupakan variabel pemeriksaan pajak, dan " $\mathrm{b}_{2} \mathrm{X}_{2}$ " merupakan variabel sanksi perpajakan. 


\section{HASIL PENELITIAN DAN PEMBAHASAN \\ 4.1. Hasil Penelitian \\ Demografi Responden}

Tabel 1. Demografi Responden

\begin{tabular}{|c|c|c|c|}
\hline \multicolumn{2}{|c|}{ Keterangan } & \multirow{2}{*}{$\frac{\mathbf{n}}{26}$} & \multirow{2}{*}{$\frac{\text { Persentasee }(\%)}{42}$} \\
\hline Jenis & Pria & & \\
\hline Kelamin & Wanitaa & 37 & 58 \\
\hline \multirow{5}{*}{ Umur } & Total & 63 & 100 \\
\hline & $<25$ TAHUN & 3 & 4.0 \\
\hline & 26 - 35 TAHUN & 34 & 55.0 \\
\hline & 36 - 45 TAHUN & 16 & 25.0 \\
\hline & $>46$ TAHUN & 10 & 16.0 \\
\hline \multirow{3}{*}{ Pekerjaan } & Total & 63 & 100 \\
\hline & Orang Pribadi & 51 & 81 \\
\hline & Badan & 12 & 19 \\
\hline \multirow{5}{*}{ Pendidikan } & Total & 63 & 100 \\
\hline & SMA & 17 & 27.0 \\
\hline & Sarjana & 29 & 46.0 \\
\hline & Magister & 3 & 4.0 \\
\hline & Lainnya & 14 & 23.0 \\
\hline \multicolumn{2}{|r|}{ Total } & 63 & 100 \\
\hline
\end{tabular}

Sumber: Data Hasil Olahan, 2018

Hasil Uji Validitas dan Uji Reliabilitas Data. Berdasarkan hasil Uji Validitas dan Uji Reliabilitas diperoleh hasil dimana $r_{\text {hitung }}>r_{\text {kritis }}$, dapat diartikan bahwa kuesioner tersebut adalah valid dan juga reliabel. Sehingga uji yang selanjutnya dapat dilakukan.

\section{Hasil Uji Asumsi Klasik}

a. Uji Normalitas, diketahui nilai signifikansi adalah 0,231 (>dari $\alpha 0,05$ ), sehingga diperoleh kesimpulan data berdistribusi normal.

b. Uji Multikolinearitas, diketahui nilai toleransi dan nilai VIF adalah sama 1,000, sehingga disimpulkan tidak terjadi multikolinearitas.

c. Uji Heteroskedastisitas, diketahui nilai signifikansi adalah 1,000 (>dari $\alpha 0,05$ ), sehingga diperoleh kesimpulan bahwa homoskedastisitas.

\section{Hasil Uji Regresi Linear Berganda}

a. Analisis Koefisien Determinasi (Uji $\mathrm{R}^{2}$ ), nilai $R$ sebesar 0,383 , berarti bahwa hubungan pemeriksaan pajak, sanksi perpajakan dengan kepatuhan WP 38,3\%. Nilai adjusted $R$ square sebesar 0,147 , berarti 14,7\% kepatuhan wajib pajak dipengaruhi oleh pemeriksaan pajak dan sanksi perpajakan.

b. Uji Parsial (Uji t). Variabel Pemeriksaan Pajak, nilai $t_{\text {hitung }}$ sebesar 4,718 dan tingkat signifikansi 0,002. Maka keputusan yang diambil adalah $\mathrm{H}_{0}$ ditolak. Variabel Sanksi

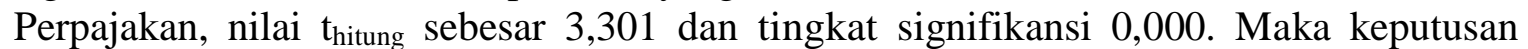
yang diambil adalah $\mathrm{H}_{0}$ ditolak.

c. Uji Simultan (Uji F), nilai $F_{\text {hitung }}$ sebesar 10,897 dengan tingkat signifikansi 0,002. Maka keputusan yang diambil adalah Ho ditolak.

d. Uji Hipotesis. Berdasarkan hasil Uji Simultan, diketahui persamaan regresi:

$$
\mathrm{Y}=44,00+(-1,144)+(-1,114)
$$

Dimana "Y" merupakan variabel kepatuhan wajib pajak, "a" merupakan nilai konstanta, " $\mathrm{b}_{1} \mathrm{X}_{1}$ " merupakan variabel pemeriksaan pajak dan " $\mathrm{b}_{2} \mathrm{X}_{2}$ " merupakan variabel sanksi perpajakan. Variabel independen akan menurunkan kepatuhan wajib pajak sebesar 44,00 
satuan. Setiap peningkatan pemeriksaan pajak (X1) berpengaruh pada penurunan tingkat ketidakpatuhan WP (Y) sebesar -1,144 satuan, jika variabel lainnya tetap. Setiap peningkatan sanksi perpajakan (X2) berpengaruh terhadap kepatuhan WP (Y) sebesar -1,114 satuan, jika variabel lainnya tetap.

\subsection{Pembahasan}

Berdasarkan uji parsial, variabel pemeriksaan pajak mempunyai nilai $t_{\text {hitung }}>t_{\text {tabel }}$ $(4,718>2,000)$ tingkat signifikansi<0,05 $(0,000<0,05)$, maka dapat ditarik kesimpulan terdapat pengaruh antara pemeriksaan pajak terhadap kepatuhan WP. Sesuai dengan penelitian yang dilakukan Mandagi (2014) yang mengatakan pemeriksaan perpajakan berpengaruh secara signifikan terhadap ketidakpatuhan WP. Sejalan dengan penelitian yang dilakukan oleh Prajogo (2013) yang menunjukkan bahwa tingkat pemahaman peraturan dan kualitas pelayanan petugas serta presepsi atas sanksi perpajakan berpengaruh terhadap kepatuhan membayar pajak. Berdasarkan uji parsial, variabel sanksi perpajakan mempunyai nilai $t_{\text {hitung }}>t_{\text {tabel }}(4,175>1,988)$ tingkat signifikansi $<0,05(0,000<0,05)$, maka ditarik kesimpulan terdapat pengaruh antara sanksi perpajakan terhadap kepatuhan WP. Sesuai dengan penelitian yang dilakukan Ngadiman dan Huslin (2015) di KPP Pratama Jakarta Kembangan yang menyatakan bahwa sanksi perpajakan berpengaruh positif terhadap kepatuhan WP. Sejalan dengan penelitian yang dilakukan oleh Sasmita (2013) di Semarang yang menyatakan ditemukan pengaruh sanksi perpajakan terhadap kepatuhan WP, yang signifikan dan positif. Menurut Sasmita (2013), pengaruh positif ini menunjukkan bahwa semakin baik dan tegasnya sanksi perpajakan yang diterapkan, maka akan menurunkan tingkat ketidakpatuhan WP, begitu pula sebaliknya. Variabel pemeriksaan pajak dan sanksi perpajakan terhadap kepatuhan wajib pajak mempunyai nilai $F_{\text {hitung }}>F_{\text {tabel }}(10,897>3,15)$ dan tingkat signifikansi $<0,05(0,000<0,05)$, sehingga disimpulkan variabel independen pemeriksaan pajak (X1) dan sanksi perpajakan (X2), berpengaruh terhadap variabel dependen kepatuhan wajib pajak (Y) secara simultan.

\section{KESIMPULAN DAN SARAN}

\subsection{Kesimpulan}

Dalam bagian akhir dari penelitian ini, diperoleh kesimpulan pemeriksaan pajak dan sanksi perpajakan terhadap kepatuhan WP, memiliki pengaruh yang signifikan dan positif. Sehingga dapat diartikan semakin tinggi tingkat sanksi perpajakan, akan meningkatkan tingkat kepatuhan WP. Pemeriksaan pajak dan sanksi perpajakan berpengaruh sebesar 53\% terhadap kepatuhan WP.

\subsection{Saran}

Berdasarkan kesimpulan tersebut, saran yang dapat diberikan peneliti sebagai masukkan kepada KPP Pratama Manado, yaitu agar kantor pelayanan pajak segera melakukan peninjauan ulang dan melakukan pengawasan terhadap pelaksanaan pemeriksaan pajak sehingga dapat menjalankan perannya dengan lebih maksimal.

\section{DAFTAR PUSTAKA}

Agoes, Sukrisno dan Estralita. 2013. Akuntansi Perpajakan, Edisi 3. Jakarta: Salemba Empat. Amanda, Cynthia Pradisti. 2014. Pengaruh Kesadaran Wajib Pajak, Sanksi Pajak, Pelayanan Fiskus, Dan Pemeriksaan Pajak Terhadap Kepatuhan Wajib pajak Orang Pribadi Di Kota Padang. Jurnal Fakultas Ekonomi Vol. 4, No. 1.

Jaya, Ida Bagus Meindra. 2016. Pengaruh Kesadaran, Kualitas Pelayanan, Pemeriksaan dan Sanksi Perpajakan pada Kepatuhan Wajib Pajak Restoran. E-Jurnal Akuntansi Udayana Vol. 16.1 Juli: 471-500 
Mandagi, Chorras. 2014. Pengaruh Pemeriksaan Pajak Terhadap Tingkat Kepatuhan Wajib Pajak Badan Dalam Memenuhi Kewajiban Perpajakannya Pada KPP Pratama Manado. Jurnal Emba Vol. 2 No. 3 September, Hal. 1665-1674.

Mardiasmo. 2016. Perpajakan Edisi Terbaru 2016. Yogyakarta: Penerbit ANDI.

Mutia, Sri Putri Tita. 2014. Pengaruh Sanksi Perpajakan, Kesadaran Perpajakan, Pelayanan Fiskus, Dan Tingkat Pemahaman Terhadap Kepatuhan Wajib Pajak Orang Pribadi (Studi Empiris pada Wajib Pajak Orang Pribadi yang terdaftar di KPP Pratama Padang). Jurnal Akuntansi, 2(1).

Ngadiman, dan Daniel Huslin. 2015. Pengaruh Sunset Policy, Tax Amnesty, dan Sanksi Pajak Terhadap Kepatuhan Wajib Pajak (Studi Empiris di Kantor Pelayanan Pajak Pratama Jakarta Kembangan). Jurnal Akuntansi Vol.XIX No.02, Mei 2015: 225-241.

Prajogo, Josepine Nidya. 2013. Pengaruh Tingkat Pemahaman Peraturan Pajak Wajib pajak, Kualitas Pelayanan Petugas Pajak, dan Persepsi Atas Sanksi Perpajakan Terhadap Kepatuhan Wajib pajak UMKM di Wilayah Sidoarjo. Tax \& Accounting Review, Vol. 3, No. 2.

Prawagis, Febirizki Damayanty. 2016. Pengaruh Pemahaman Atas Mekanisme Pembayaran Pajak, Persepsi Tarif Pajak dan Sanksi Pajak Terhadap Kepatuhan Wajib Pajak UMKM. Jurnal Perpajakan (JEJAK) Vol. 10 No. 1.

Resmi, Siti. 2013. Perpajakan, Teori dan Kasus Edisi 7. Buku 1. Jakarta: Salemba Empat.

Santoso S., 2014. Statistik Parametris Edisi Revisi. Jakarta: Penerbit PT Elex Media Komputindo.

Sasmita, Sentya N. Arum. 2013. Pengaruh Pemahaman Wajib Pajak, Pelayanan Fiskus, Kesadaran Wajib Pajak dan Sanksi Perpajakan Terhadap Kepatuhan Wajib Pajak Pemilik Usaha Kecil Menengah Dalam Pelaporan Kewajiban Perpajakan Di Semarang (Studi UMKM Di Kota Semarang). Artikel Ilmiah. Semarang: Fakultas Ekonomi dan Bisnis Universitas Diponegoro.

Sugiyono, 2013. Metode Penelitian Bisnis. Bandung: Penerbit Alfabeta.

Sugiyono, 2014. Cara Mudah Menyusun: Skripsi, Tesis, dan Disertasi. Bandung: Penerbit Alfabeta.

Tunggal, Amin Wijaya. 2012. Pengantar Akuntansi Keuangan. Jakarta: Harvarindo.

Utami, Renny Sri. 2013. Pengaruh Sanksi Perpajakan Terhadap Kepatuhan Wajib Pajak Dan Implikasinya Pada Penerimaan Pajak (Survey pada KPP Pratama di Kanwil Jabar 1). Diakses pada: http://elib.unikom.ac.id/files/disk1/641/jbptunikompp-gdlrennysriut-32046-11-unikom_r-1.pdf.

Waluyo, 2011. Perpajakan Indonesia, Edisi 10. Jakarta: Salemba. 